Quim. Nova, Vol. 35, No. 8, 1686-1691, 2012

\title{
MINIPROJETO PARA ENSINO DE QUÍMICA GERAL EXPERIMENTAL BASEADO NA FERMENTAÇÃO DO CALDO DE CANA-DE-AÇÚCAR
}

\author{
Carlos Roberto de Menezes Peixoto*, Gilber Ricardo Rosa, Camila Nunes da Silva, Bianca Trevizan dos Santos e Tamiris \\ Lima Engelmann
}

Escola de Química e Alimentos, Universidade Federal do Rio Grande, Campus Santo Antônio da Patrulha, Rua Barão do Cahy, 125, 95500-000 Santo Antônio da Patrulha - RS, Brasil

Recebido em 31/10/11; aceito em 17/2/12; publicado na web em 15/6/12

\begin{abstract}
MINI-PROJECT ON FERMENTATION OF SUGARCANE JUICE FOR PRACTICAL GENERAL CHEMISTRY COURSES. This paper describes a five-week mini-project for a general chemistry laboratory course. Activities are included preparations of ethanol and sucrose solutions, calculation of concentrations, determination of densities with densimeters, sugarcane juice fermentation with $\mathrm{CO}_{2}$ capture in alkaline solution, distillation, and determination of amounts of ethanol and $\mathrm{CO}_{2}$ formed. Abilities and concepts normally present in practical general chemistry courses are covered: use of balances, volumetric glassware and densimeters, preparation of solutions, performing of dilutions, determination of solution densities, observation of chemical reactions, stoichiometric calculations, separation of mixtures, and titration.
\end{abstract}

Keywords: sugar cane; fermentation; chemical education.

\section{INTRODUÇÃO}

Na fermentação do caldo da cana-de-açúcar ocorre a reação química, catalisada por enzimas produzidas por leveduras, de quebra da molécula de sacarose em glicose e frutose (enzima invertase) e posterior transformação em etanol e gás carbônico (enzima zimase). A reação global está representada abaixo:1,2

$\mathrm{C}_{12} \mathrm{H}_{22} \mathrm{O}_{11(\mathrm{aq})}+\mathrm{H}_{2} \mathrm{O}_{(\mathrm{l})} \rightarrow 4 \mathrm{C}_{2} \mathrm{H}_{6} \mathrm{O}_{(\mathrm{aq})}+4 \mathrm{CO}_{2(\mathrm{~g})}$

(Reação 1)

A separação do etanol do mosto após a fermentação é feita por destilação. Usando-se colunas de destilação fracionada eficientes pode-se obter etanol com teor de 97,2\% v/v, chamado de etanol hidratado, que pode ser usado como combustível. Teor acima deste não pode ser obtido por destilação, porque etanol e água formam uma mistura azeotrópica, sendo necessários outros processos de separação. $\mathrm{O}$ álcool adicionado à gasolina é o etanol anidro, que apresenta teor acima de 99,0\% v/v. ${ }^{3}$ A cachaça apresenta entre 38-48\% v/v de etanol e é obtida pela destilação do mosto em alambiques, que não apresentam coluna de destilação fracionada, portanto, um processo de separação menos eficiente. ${ }^{4}$

O Brasil produziu cerca de 18,1 bilhões de L de etanol hidratado, na safra 2008/2009, e cerca de 9,3 bilhões de L de etanol anidro. ${ }^{5}$ Também produziu 1,4 bilhões de L de cachaça, que é a bebida destilada mais consumida no Brasil e a terceira no mundo. ${ }^{6}$ Os estados de São Paulo, Minas Gerais, Paraná, Goiás, Mato Grosso do Sul, Mato Grosso, Alagoas e Pernambuco são os maiores produtores de cana-de-açúcar do Brasil. No Rio Grande do Sul, devido ao clima frio, apenas em algumas regiões a produção de etanol em larga escala é viável economicamente; existe apenas uma usina na região noroeste do estado, no município de Porto Xavier. Entretanto, a produção da cachaça é bastante difundida entre pequenos agricultores. No município de Santo Antônio da Patrulha a cana-de-açúcar foi implantada pelos colonizadores açorianos, no século XIX. O município apresenta clima e solo propícios para o cultivo, sendo tradicional produtor de derivados da cana, entre eles cachaça e rapadura. O município também

\footnotetext{
*e-mail: carlospeixoto@furg.br
}

contava, nas décadas de 1960 e 70, com uma usina para produção de etanol hidratado em larga escala, entretanto, devido ao relevo irregular e à dificuldade de mecanização da lavoura, a atividade se tornou inviável economicamente. ${ }^{7}$

A produção de etanol é uma área de atuação de diferentes profissionais, entre eles químicos, engenheiros agroindustriais, engenheiros químicos, engenheiros de alimentos, agrônomos, engenheiros agrícolas, farmacêuticos e nutricionistas, sendo abordada como conteúdo curricular em disciplinas como tecnologia de fermentações e tecnologia de bebidas. Entretanto, como um processo químico de grande importância e uso por diferentes profissionais, também apresenta potencial para uso em ensino inicial de Química de diferentes cursos superiores e também ensino médio, demonstrando aplicações da Química de forma motivadora e conectada com a realidade, sendo que em alguns trabalhos esse potencial foi explorado. O trabalho de Pinheiro et al. ${ }^{8}$ apresentou um histórico da produção da cachaça no Brasil, seus aspectos sociais e econômicos e, também, sua composição química. No trabalho de Ferreira et al. ${ }^{9}$ é descrito um experimento simples para ser aplicado em ensino médio, onde ocorre a fermentação e, para evidenciar a formação do $\mathrm{CO}_{2}$, o gás é capturado em solução de $\mathrm{Ca}(\mathrm{OH})_{2}$ formando precipitado visível de $\mathrm{CaCO}_{3}$. Já no trabalho de Silva, ${ }^{10}$ é descrita uma proposta integrada para uso da fermentação do caldo-de-cana em ensino de Química, História, Biologia e Geografia.

Este trabalho descreve o uso de um miniprojeto, baseado neste processo, para ensino de Química em disciplinas de Química Geral Experimental em cursos superiores. O termo miniprojeto foi usado por Carriazo ${ }^{11}$ ao se referir a uma atividade experimental em que os alunos gastam algumas semanas para sua execução, tipicamente entre 4 e 6. Carriazo ${ }^{11}$ fez o uso de miniprojeto em disciplina de Química Inorgânica Experimental. Outros trabalhos encontrados na literatura também apresentam propostas de ensino para disciplinas experimentais de Química que poderiam ser consideradas como miniprojetos, apesar dos autores não fazerem uso deste termo, por exemplo, os trabalhos de Formiga (para ensino de Química de Coordenação), ${ }^{12}$ Murtinho (para ensino integrado de Química Orgânica, Química de polímeros e Fotoquímica), ${ }^{13}$ e Simoni (para Química Geral Experimental). ${ }^{14}$ Segundo esses autores, foi observada maior motivação nos alunos para a realização destas propostas se comparada à 
realização de atividades isoladas e sem interrelação entre elas.

Os objetivos e a forma de aplicação de um miniprojeto podem variar em função da disciplina onde é usado, sendo possível trabalhar conhecimentos teóricos e habilidades básicas necessárias para realização de atividades em laboratório, no caso de disciplinas iniciais. ${ }^{14}$ Em disciplinas oferecidas a alunos em estágios mais avançados de formação podem ser trabalhados, além de conhecimentos em química mais avançados, também revisão da literatura, montagem de projeto, interpretação dos resultados e redação de relatório ou artigo científico. ${ }^{11-13}$

No presente trabalho, o termo miniprojeto foi usado para descrição das atividades envolvendo o processo de fermentação do caldo de cana, usadas durante 5 semanas na disciplina de Introdução a Práticas de Laboratório, dos cursos de Engenharia Agroindustrial: Agroquímica e Engenharia Agroindustrial: Indústrias Alimentícias, da Universidade Federal do Rio Grande, Campus Santo Antônio da Patrulha. Esta é uma disciplina experimental, de 2 períodos semanais, oferecida no $1^{\circ}$ semestre aos dois cursos. A experiência foi usada para trabalhar habilidades e conceitos envolvidos na ementa da disciplina: uso de vidrarias para medidas volumétricas, uso de balança, preparo de soluções, diluições, densidade de soluções, uso de densímetros, reações químicas, estequiometria, separação de misturas e titulação. Foram realizadas todas as etapas para obtenção do álcool hidratado ou da cachaça. Além da fermentação, foram realizadas as operações necessárias para determinação dos teores de açúcar no caldo de cana antes e depois da fermentação, do teor de etanol no produto obtido, das quantidades de etanol produzido e de gás carbônico liberado, relacionando com a quantidade de açúcar presente inicialmente.

\section{PARTE EXPERIMENTAL}

As 4 turmas, 2 de cada curso, contendo no máximo 25 alunos, foram divididas em grupos de 2 ou 3 alunos. O experimento foi iniciado na $3^{\mathrm{a}}$ aula, sendo que anteriormente os alunos tiveram aulas sobre segurança em laboratório e vidrarias. Um roteiro do experimento foi preparado para ser realizado pelos alunos durante 5 semanas, considerando-se uma aula de 2 períodos (100 $\mathrm{min}$ ) por semana.

\section{Materiais}

Para a execução das 5 aulas, para cada grupo de alunos, serão necessários balões volumétricos de 100, 250 e $500 \mathrm{~mL}$, pipetas volumétricas de 10,20 e $50 \mathrm{~mL}$, um béquer de $50 \mathrm{~mL}$ e dois de $100 \mathrm{~mL}$, alcoômetro $\left(0-100^{\circ} \mathrm{GL}\right.$, div. $\left.1^{\circ} \mathrm{GL}\right)$, termômetro, duas espátulas, dois vidros de relógio, um sacarímetro de Brix (0-30 ${ }^{\circ}$ Brix, div. $\left.1^{\circ} \mathrm{Brix}\right)$, provetas de 50,250 e $500 \mathrm{~mL}$, três erlenmeyers de $100 \mathrm{~mL}$ e um de $500 \mathrm{~mL}$, mangueira de silicone com tubos de vidro nas extremidades, balão de fundo redondo de $500 \mathrm{~mL}$, conector balão-condensador, condensador, conector condensador-recipiente de coleta, recipiente para coleta do produto de destilação, elevador e bureta de $50 \mathrm{~mL}$.

\section{Reagentes}

Os reagentes a serem usados são etanol hidratado comercial, açúcar comercial, hidróxido de sódio, ácido clorídrico concentrado, fermento para panificação resfriado, caldo de cana, fenolftaleína e água destilada.

\section{Equipamentos}

Serão usadas uma balança semianalítica, uma chapa de aquecimento, um banho-maria com controle de temperatura e uma manta de aquecimento para balão de $500 \mathrm{~mL}$.

\section{$11^{\mathrm{a}}$ aula: Diluição de soluções água/etanol}

Os estudantes prepararão soluções água/etanol e testarão a metodologia que será usada para determinação da concentração de etanol no destilado que será obtido na 4a aula.

\section{Procedimento}

Cada grupo deverá pesar um balão volumétrico de $100 \mathrm{~mL}$. Com pipeta volumétrica, adicionar o volume adequado de etanol comercial ao balão e completar o volume com água destilada. Pesar novamente para determinar a massa da solução. Na sequência, colocar a solução em proveta de $100 \mathrm{~mL}$ e medir o teor de etanol usando um alcoômetro. Repetir o procedimento 7 vezes, usando volumes de $0,10,20$, $30,40,50$ e $100 \mathrm{~mL}$ de etanol comercial na preparação das soluções

\section{Tratamento dos dados}

Tendo-se a massa (m) de cada solução e seu volume (v), calcular a densidade $(\mathrm{d}=\mathrm{m} / \mathrm{v})$. Usando uma tabela de valores de concentração de soluções água/etanol em função da densidade, obtida na literatura, ${ }^{15} \mathrm{o}$ valor da concentração da solução deverá ser determinado. Calcular também as concentrações usando a expressão da diluição de soluções: $C_{i} V_{i}=C_{f} V_{f}$ (onde $C_{i}$ e $C_{f}$ são as concentrações inicial e final de etanol e $V_{i}$ e $V_{f}$ são os volumes inicial e final). A concentração inicial, $\mathrm{C}_{\mathrm{i}}$, é a concentração da solução de etanol obtida sem a adição de água. Com os dados coletados os alunos poderão montar uma tabela contendo para cada solução o volume de etanol comercial adicionado, a densidade da solução e as concentrações de etanol obtidas a partir da medida da densidade, com o uso do alcoômetro e pela equação $\mathrm{C}_{\mathrm{i}} \mathrm{V}_{\mathrm{i}}=\mathrm{C}_{\mathrm{f}} \mathrm{V}_{\mathrm{f}}$ (Tabela 1 ). Comparar os resultados obtidos pelos diferentes métodos.

A tabela obtida da ref. 15 fornece valores de concentração de soluções água/etanol em função da densidade na temperatura de 20 ${ }^{\circ} \mathrm{C}$. O alcoômetro também é calibrado para uso nessa temperatura. Portanto, temperaturas diferentes podem causar desvios nos valores obtidos.

\section{2⿳a aula: Preparo de soluções}

Os estudantes prepararão soluções aquosas de sacarose e testarão a metodologia que será usada para determinação do teor de açúcar no caldo de cana durante a 3a aula. Também serão produzidas soluções de $\mathrm{NaOH}$ e $\mathrm{HCl}$, que serão usadas para determinação da quantidade de $\mathrm{CO}_{2}$ liberada durante o processo de fermentação, durante a $5^{\mathfrak{a}}$ aula.

\section{1a parte: Preparação das soluções de sacarose}

\section{Procedimento}

Em balão volumétrico de $250 \mathrm{~mL}$, previamente pesado, os alunos prepararão uma solução de sacarose adicionando a massa adequada de açúcar comercial e completando o volume com água destilada. Pesar novamente para determinar a massa da solução por diferença. Posteriormente, a solução deverá ser colocada em proveta de $250 \mathrm{~mL}$ e medida a concentração de sacarose através do uso do sacarímetro de Brix. Todo o procedimento deverá ser repetido usando-se as massas de 0,$0 ; 12,5 ; 25,0 ; 37,5 ; 50,0$ e $62,5 \mathrm{~g}$ de sacarose.

\section{Tratamento dos dados}

Conhecendo a massa de açúcar adicionado e a massa da solução, calcular a concentração de sacarose em graus Brix $\left(1^{\circ}\right.$ Brix $=1 \mathrm{~g}$ de sacarose por $100 \mathrm{~g}$ de solução). Calcular também a densidade da solução $(d=m / v)$ e, usando uma tabela de concentração de sacarose em função da densidade da solução, ${ }^{1}$ determinar as concentrações de cada uma. Montar uma tabela (Tabela 2) contendo, para cada solução, 
a massa de sacarose adicionada, a massa da solução, o teor de sacarose ( ${ }^{\circ}$ Brix) calculado pela massa adicionada e massa total da solução, a densidade da solução, o teor de sacarose obtido pela relação com a densidade e o teor de sacarose medido usando-se o sacarímetro. Comparar os resultados de concentração obtidos por cada método.

Os dados de concentração em função da densidade da tabela da ref. 1 são válidos para a temperatura de $20^{\circ} \mathrm{C}$, e o sacarímetro também é calibrado para uso nesta temperatura. Portanto, assim como para as soluções etanol/água, temperaturas diferentes desta podem causar desvios nos resultados.

\section{2ª parte: Preparação da solução de hidróxido de sódio \\ Procedimento}

Os alunos deverão calcular a massa de $\mathrm{NaOH}$ necessária para o preparo de $500 \mathrm{~mL}$ de solução $2 \mathrm{~mol} / \mathrm{L}$. Posteriormente, pesar tal massa, diluir em béquer de $100 \mathrm{~mL}$, transferir para balão volumétrico de $500 \mathrm{~mL}$ e completar o volume com água destilada. Utilizar capela de exaustão durante esta etapa devido aos vapores cáusticos liberados.

\section{3a parte: Preparação da solução de ácido clorídrico} Procedimento

Com os dados de densidade e teor coletados no frasco de $\mathrm{HCl}$ concentrado, os estudantes determinarão o volume necessário do mesmo para o preparo de $100 \mathrm{~mL}$ de solução $2 \mathrm{~mol} / \mathrm{L}$. Utilizando capela de exaustão, coletar tal volume de ácido com proveta de 50 $\mathrm{mL}$ e, após, transferir para balão volumétrico de $100 \mathrm{~mL}$. A adição prévia de certa quantidade de água destilada no balão volumétrico evita o risco de projeções quando da mistura do ácido concentrado. Na sequência, o balão deverá ser completado com água destilada até a marca de aferição.

É importante que a solução de $\mathrm{HCl}$ seja preparada com muita precisão, já que não será padronizada e será usada em titulação na 5 a aula. Vale ressaltar que a proposta de aula prática aqui apresentada foi desenvolvida para calouros e o tema padronização será desenvolvido na sequência do curso. Entretanto, caso o professor julgue conveniente, a padronização pode ser feita.

\section{3 aula: Fermentação do caldo de cana-de-açúcar}

Os estudantes fermentarão o caldo de cana-de-açúcar e evidenciarão a reação química de transformação da sacarose em etanol e dióxido de carbono (Reação 1) pela observação da liberação do gás durante o processo.

$\mathrm{O}$ gás $\mathrm{CO}_{2}$ será coletado na solução de $\mathrm{NaOH}$, preparada na $2^{\underline{a}}$ aula, para posterior quantificação através de titulação com $\mathrm{HCl}$ (5 aula).

\section{Procedimento}

Os grupos de laboratório inicialmente determinarão a concentração de sacarose do caldo de cana-de-açúcar via sacarímetro de Brix. Normalmente, o teor de sacarose fica em torno de 20-22 ${ }^{\circ}$ Brix, porém, é necessário proceder à diluição prévia, de modo que a concentração fique entre $14-16^{\circ}$ Brix. Com o auxílio da expressão da diluição $\left(\mathrm{C}_{\mathrm{i}} \mathrm{V}_{\mathrm{i}}=\mathrm{C}_{\mathrm{f}} \mathrm{V}_{\mathrm{f}}\right)$, os alunos determinarão o volume de caldo de cana-de-açúcar necessário para preparar $250 \mathrm{~mL}$ de mosto com teor de sacarose de $14{ }^{\circ}$ Brix. Medir este volume em proveta e completar até $250 \mathrm{~mL}$ com água destilada. Transferir para erlenmeyer de 500 $\mathrm{mL}$, previamente pesado, e pesar o erlenmeyer novamente depois da adição para determinação da massa de mosto usada e sua densidade. Após, deverão ser pesadas cerca de $9 \mathrm{~g}$ de fermento biológico de panificação resfriado em béquer de $100 \mathrm{~mL}$ e dissolvido em cerca de $2 \mathrm{~mL}$ de caldo de cana-de-açúcar, previamente aquecido à 30 ${ }^{\circ} \mathrm{C}$. O fermento deverá ser ativado em banho-maria, mantendo-se a temperatura anterior por cerca de $10 \mathrm{~min}$. Enquanto o fermento é pré-ativado, os alunos adicionarão $400 \mathrm{~mL}$ da solução de $\mathrm{NaOH}$ preparada na aula anterior em uma proveta de $500 \mathrm{~mL}$, estocando os $100 \mathrm{~mL}$ restantes para uso na $5^{\mathrm{a}}$ aula. Tendo o fermento pronto, será adicionado ao erlenmeyer de $500 \mathrm{~mL}$, que contém o mosto com teor de sacarose de $14{ }^{\circ}$ Brix, e imediatamente posto em banho-maria a $30^{\circ} \mathrm{C}$, coletando o $\mathrm{CO}_{2}$ na proveta com solução de $\mathrm{NaOH}$. O sistema usado está representado na Figura 1. A fermentação deverá ocorrer por aproximadamente $24 \mathrm{~h}$.

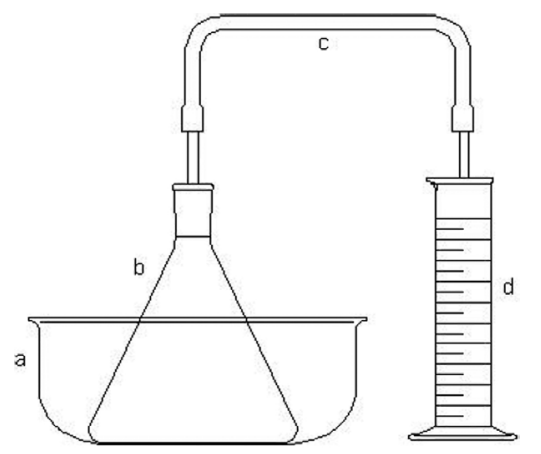

Figura 1. Aparelhagem montada para fermentação do caldo de cana-de-açúcar contendo banho-maria (a), erlenmeyer de $500 \mathrm{~mL}$ (b), mangueira de silicone com tubos de vidro nas extremidades, um deles inserido no erlenmeyer através da rolha furada e outro mergulhado na solução de $\mathrm{NaOH}$, (c) e proveta de $500 \mathrm{~mL}(\mathrm{~d})$

\section{Tratamento dos dados}

Além do uso do sacarímetro, determinar a densidade do mosto e o teor de sacarose usando a tabela de concentração em função da densidade. Comparar os resultados obtidos pelos dois métodos.

Conhecendo o teor de sacarose e a massa total do mosto inicialmente, determinar a massa de sacarose e sua quantidade em mols. Determinar o rendimento teórico da reação, ou seja, a quantidade de etanol e $\mathrm{CO}_{2}$, inicialmente em mols (de acordo com a Reação 1) e depois em gramas, que poderão ser formadas, para comparação com as quantidades obtidas experimentalmente que serão determinadas na $4^{\mathrm{a}}$ e $5^{\mathrm{a}}$ aulas, e determinação do rendimento da reação.

\section{4a aula: Destilação do mosto}

Durante esta etapa os alunos procederão à destilação do mosto, que deverá ser realizada logo após o processo de fermentação (um horário alternativo foi negociado com os alunos para que a $4^{\mathrm{a}}$ aula fosse realizada 24 h após a 3a aula). Se o intuito é obter etanol, o aparelho de destilação deverá conter uma coluna de fracionamento de Vigreux para otimizar a separação. Como no experimento desenvolvido o objetivo era de produzir cachaça, utilizou-se aparelho de destilação simples (Figura 2). O teor alcoólico no produto final deverá ser medido para cálculo posterior de rendimento do processo.

\section{Procedimento}

Após a fermentação, cada grupo deverá retirar do banho-maria seu erlenmeyer contendo o mosto fermentado e transferi-lo para um balão de fundo redondo de $500 \mathrm{~mL}$. A aparelhagem mostrada na Figura 2 deve ser montada. O recipiente que coletará o destilado deverá ser previamente pesado. Em seguida, iniciar o aquecimento e a destilação deverá ser finalizada quando a temperatura atingir $97^{\circ} \mathrm{C}$. Terminando o processo, os estudantes determinarão a massa de destilado e dele retirarão uma alíquota de $10 \mathrm{~mL}$ com pipeta volumétrica e, determinando sua massa, obterão a densidade do destilado. 


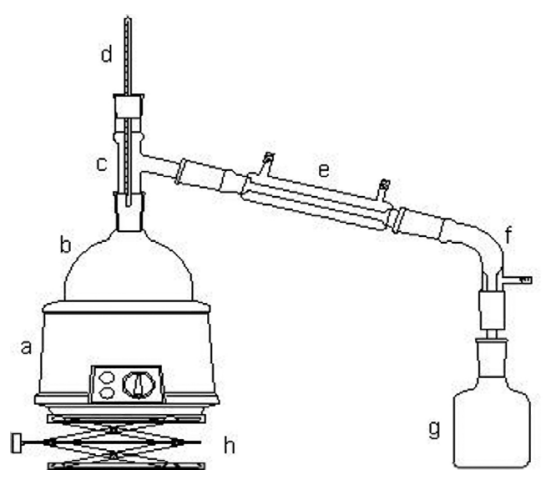

Figura 2. Aparelhagem de destilação simples utilizada para obtenção de cachaça contendo manta de aquecimento (a), balão de fundo redondo de $500 \mathrm{~mL}(\mathrm{~b})$, conector balão-condensador (c), termômetro (d), condensador (e), conector condensador-recipiente de coleta $(f)$, recipiente para coleta do produto $(g)$ e elevador $(h)$

\section{Tratamento dos dados}

Conhecendo a massa do destilado (m) e sua densidade (d), calcular o volume de produto obtido $(\mathrm{v}=\mathrm{m} / \mathrm{d})$. Conhecendo a densidade também determinar o teor de etanol no destilado através de tabela que correlaciona concentração com densidade. ${ }^{15}$ Uma medição direta via alcoômetro fica inviável por se tratar de um volume de destilado pequeno. A partir do teor de etanol e volume total do destilado determinar o volume de etanol presente. Usando este volume, e considerando a densidade do etanol puro, determinar a massa de etanol obtido. Determinar o rendimento da reação, considerando o rendimento teórico calculado na 3 a aula.

\section{5a aula: Determinação da quantidade de gás carbônico liberada na fermentação}

Esta é a última parte de todo procedimento e visa a determinação da quantidade de $\mathrm{CO}_{2}$ formada durante o processo de fermentação. Assim, os alunos titularão as duas partes da solução de $\mathrm{NaOH}$ preparada na $2^{\underline{a}}$ aula, a parte armazenada $(100 \mathrm{~mL})$ e a parte usada para coleta do $\mathrm{CO}_{2}$ da fermentação na 3 a aula $(400 \mathrm{~mL})$. Essa última teve a quantidade de $\mathrm{NaOH}$ reduzida pela passagem do $\mathrm{CO}_{2}$ (Reação 2) e, pela diferença entre o número de mols de $\mathrm{OH}^{-}$presente na solução antes e após a coleta do gás, será determinada sua quantidade.

$$
\mathrm{CO}_{2}(\mathrm{~g})+\mathrm{OH}^{-}(\mathrm{aq}) \rightarrow \mathrm{HCO}_{3}^{-}(\mathrm{aq}) \quad(\text { Reação } 2)
$$

\section{Procedimento}

Os alunos preencherão uma bureta de $50 \mathrm{~mL}$ com a solução de $\mathrm{HCl} 2 \mathrm{~mol} / \mathrm{L}$ preparada na $2^{\underline{a}}$ aula. Com pipeta volumétrica, em erlenmeyer de $100 \mathrm{~mL}$, adicionar $20 \mathrm{~mL}$ da solução de $\mathrm{NaOH}$ armazenada na $2^{\mathrm{a}}$ aula juntamente com 2 gotas de indicador fenolftaleína $1 \% \mathrm{~m} / \mathrm{v}$ (dissolvida em mistura água/etanol 60:40, previamente preparado e disponibilizado). A titulação ocorrerá até mudança de coloração de rosa para incolor. O volume de ácido consumido deverá ser anotado, repetindo-se o procedimento por mais duas vezes. A solução de $\mathrm{NaOH}$ usada para captura do $\mathrm{CO}_{2}$ na 3a aula deverá ser titulada da mesma forma.

\section{Tratamento dos dados}

Através dos volumes da solução de $\mathrm{HCl}$ gastos nas titulações das duas soluções de $\mathrm{NaOH}$, determinar suas concentrações e as quantidades de $\mathrm{NaOH}$ em mols presentes nos $400 \mathrm{~mL}$ antes e depois da captura do $\mathrm{CO}_{2}$ da fermentação. Pela diferença, determina-se a quantidade de $\mathrm{OH}^{-}$neutralizada e, em consequência, de acordo com a estequiometria da Reação 2, a quantidade de $\mathrm{CO}_{2}$, inicialmente em mols e depois em gramas, formada na fermentação e capturada. Determinar o rendimento da reação, considerando o rendimento teórico calculado na $3^{\mathrm{a}}$ aula.

\section{RESULTADOS}

Nesta seção serão apresentados os resultados obtidos por um dos grupos de alunos, sendo que os demais obtiveram resultados próximos a estes, para dar uma ideia dos valores que serão encontrados, em caso de aplicação do experimento em condições semelhantes.

Nas Tabelas 1 e 2 estão representados os resultados de concentrações obtidos pelos diferentes métodos para as soluções de etanol e sacarose preparadas na $1^{\underline{a}}$ e $2^{\underline{a}}$ aulas.

No cálculo do rendimento teórico da reação feita na $3^{3}$ aula, os cálculos estequiométricos indicam que o mosto, apresentando inicialmente $14{ }^{\circ}$ Brix e massa de 264,2 g, apresentaria 37,0 g de sacarose, portanto 0,108 mols (massa molar da sacarose $=342,34 \mathrm{~g}$ ). Segundo a Reação 1, a quantidade de etanol e de gás carbônico que poderiam ser formados seria de $0,432 \mathrm{mols}$, correspondendo a um rendimento teórico de 19,9 g de etanol e 19,0 g de $\mathrm{CO}_{2}$.

$\mathrm{Na}$ 4a aula foram obtidas $39,73 \mathrm{~g}$ de cachaça com uma densidade de $0,9256 \mathrm{~g} / \mathrm{mL}$, portanto volume de $42,92 \mathrm{~mL}$ (por $\mathrm{d}=\mathrm{m} / \mathrm{v}$ ) e teor alcoólico de 53,1\% (v/v) (pela tabela da ref. 15). Logo, o volume de etanol puro obtido seria de $22,8 \mathrm{~mL}$. Considerando a densidade do etanol puro de $0,79074 \mathrm{~g} / \mathrm{mL}$, a massa obtida foi de $18,0 \mathrm{~g}$, correspondendo a um rendimento de $90,5 \%$.

$\mathrm{Na} 5^{\mathrm{a}}$ aula, na titulação dos $20 \mathrm{~mL}$ de solução de $\mathrm{NaOH}$ armazenada na 3 aula foram gastos em média $19,0 \mathrm{~mL}$ da solução de $\mathrm{HCl}$, enquanto que para titulação da solução usada na 3a aula na coleta do $\mathrm{CO}_{2}$ foram gastos $9,8 \mathrm{~mL}$. Assim sendo, a solução de $\mathrm{NaOH}$ apresentava 0,760 mols em $400 \mathrm{~mL}$ e após a coleta do $\mathrm{CO}_{2}$ apresentou 0,40 mols. Logo, 0,36 mols de $\mathrm{NaOH}$ foram neutralizados, o que

Tabela 1. Dados coletados durante o preparo de soluções água/etanol $\left(1^{\mathrm{a}}\right.$ aula $)$ a $20^{\circ} \mathrm{C}$

\begin{tabular}{cccccc}
\hline Solução* & Vol. etanol $(\mathrm{mL})$ & Densidade $(\mathrm{g} / \mathrm{mL})$ & {$[\mathrm{Et}] \mathrm{dens} . * *(\% \mathrm{v} / \mathrm{v})$} & {$[\mathrm{Et}] \mathrm{alc} . * * *(\% \mathrm{v} / \mathrm{v})$} & {$[\mathrm{Et}] \mathrm{calc} . * * * *(\% \mathrm{v} / \mathrm{v})$} \\
\hline 1 & 0 & 0,99827 & 1,2 & 10 & 0 \\
2 & 10 & 0,98393 & 12,2 & 19 & 9,6 \\
3 & 20 & 0,97480 & 20,5 & 29 & 28,8 \\
4 & 30 & 0,96383 & 30,1 & 41 & 38,4 \\
5 & 40 & 0,94480 & 41,1 & 50 & 48,0 \\
7 & 50 & 0,92756 & 52,1 & 96 & 96,0 \\
\hline
\end{tabular}

*Volume total $=100 \mathrm{~mL}$; **teor de etanol determinado pela densidade da solução, usando tabela da ref. 11; ***teor de etanol medido com uso do alcoômetro; ****teor de etanol calculado pela equação $\mathrm{C}_{\mathrm{i}} \mathrm{V}_{\mathrm{i}}=\mathrm{C}_{\mathrm{f}} \mathrm{V}_{\mathrm{f}}$. 
Tabela 2. Dados coletados durante o preparo de soluções de sacarose $\left(2^{\mathrm{a}}\right.$ aula) a $20^{\circ} \mathrm{C}$

\begin{tabular}{ccccccc}
\hline Solução* & Massa de sacarose $(\mathrm{g})$ & Massa da solução $(\mathrm{g})$ & {$[\mathrm{S}]$ calc.*** $\left({ }^{\circ}\right.$ Brix $)$} & Densidade $(\mathrm{g} / \mathrm{mL})$ & {$[\mathrm{S}]$ dens.*** $\left({ }^{\circ}\right.$ Brix $)$} & {$[\mathrm{S}]$ sac.**** $\left({ }^{\circ}\right.$ Brix $)$} \\
\hline 1 & 0,00 & 249,29 & 0,0 & 0,997 & 0,0 & 0,0 \\
2 & 12,50 & 254,11 & 4,9 & 1,016 & 4,0 & 5,3 \\
3 & 25,00 & 258,84 & 9,7 & 1,035 & 1,0 & 13,0 \\
4 & 37,50 & 263,49 & 14,2 & 1,054 & 17,4 & 14,0 \\
5 & 50,00 & 268,29 & 18,6 & 1,073 & 1,0 & 19,2 \\
6 & 62,50 & 273,04 & 22,9 & 1,092 & 2,0 & 23,7 \\
\hline
\end{tabular}

*Volume total $=250 \mathrm{~mL} ; * *$ teor de sacarose calculado pelas massas de sacarose e da solução; ***teor de sacarose determinado pela densidade da solução, usando tabela da ref. $1 ; * * * *$ teor de sacarose medido com o sacarímetro.

indica que 0,36 mols ou $16 \mathrm{~g}$ de $\mathrm{CO}_{2}$ foram liberados da fermentação (Reação 2) e capturados, correspondendo a um rendimento de $84 \%$.

\section{DISCUSSÃO}

Nas ementas de disciplinas de Química experimentais oferecidas a alunos iniciantes de cursos superiores são incluídas atividades para se trabalhar com conceitos de Química e, também, para o desenvolvimento de habilidades para trabalhos em laboratório. Os temas referentes ao uso de vidrarias para medidas volumétricas, uso da balança, preparo de soluções, diluições, densidade de soluções, uso de densímetros, reações químicas, estequiometria, separação de misturas e titulação são comuns de serem encontrados nessas ementas.

No trabalho de Simoni et al. ${ }^{16}$ foi apresentado um levantamento dos experimentos oferecidos aos diversos cursos de Química Geral Experimental da Unicamp ao longo de 35 anos. Após análise dos dados, foi proposta uma classificação para os experimentos de laboratório em Química com o objetivo de facilitar a montagem de uma disciplina de Química Geral Experimental. Os autores classificaram os experimentos em quatro categorias e definiram cada uma como descritas, de forma resumida, a seguir: conceituais (C) - envolvem conceitos fundamentais da Química; metodológicos (M) - têm como objetivo central o desenvolvimento do aluno em técnicas experimentais; fundamentais $(\mathrm{F})$ - envolvem medidas de quantidades fundamentais para a caracterização de um sistema químico e, quantitativos (Q) - envolvem determinações quantitativas de diversos gêneros.

Ainda segundos os autores, ${ }^{16}$ alguns experimentos podem ser classificados em mais de uma categoria, inclusive existindo experimentos que podem receber todas as classificações propostas. ${ }^{14}$ Foi sugerido também que uma distribuição dos experimentos dentro das quatro categorias é desejável. Nas disciplinas de Química Geral Experimental da Unicamp, no período considerado, verificou-se que $38,5 \%$ dos experimentos são conceituais, 22,2\% fundamentais, $25,8 \%$ metodológicos e $13,6 \%$ são de experimentos quantitativos. ${ }^{16}$

Esse trabalho destaca-se como um guia para avaliação das atividades de disciplinas de Química Geral Experimental e sua distribuição em função dos objetivos a serem alcançados. Em função disto, essa classificação foi usada na análise das atividades do miniprojeto proposto.

Os tópicos abordados - uso de vidrarias para medidas volumétri-



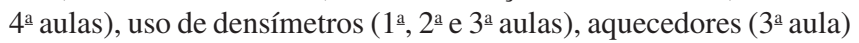
e separação de misturas (4⿳亠口冋 aula) - permitem classificar o experimento como metodológico $(\mathrm{M})$.

O conceito de reação química é abordado na $3^{\text {a }}$ aula, sendo observada visualmente pelo borbulhamento de gás na reação de transformação da sacarose em etanol e no gás $\mathrm{CO}_{2}$. Por isso, o experimento pode ser classificado como conceitual $(\mathrm{C})$.
A titulação ácido-base realizada na 5a aula é uma atividade típica de experimento quantitativo (Q), mas as determinações de concentrações a partir de densidades e do uso de densímetros (1 $1^{\mathrm{a}}, 2^{\mathrm{a}}$, $3^{3}$ e e $4^{\mathrm{a}}$ aulas) também contribuem para esta classificação. Entretanto, como sugerido por Simoni, ${ }^{16}$ devido ao nível de formação dos alunos nesse estágio e ao fato de que técnicas quantitativas serão novamente abordadas nas disciplinas de Química Analítica, o rigor nos resultados analíticos não é o mais importante nesta etapa. Nos resultados de cálculos e medidas de concentrações realizadas na $1^{\underline{a}}$ e $2^{\underline{a}}$ aulas (Tabelas 1 e 2), podem-se observar alguns desvios, que são aceitáveis para os objetivos do experimento, podendo ser devidos a desvios nos volumes das vidrarias usadas, certas variações de temperatura, ou ainda à falta de experiência dos alunos.

No cálculo do rendimento da reação pela quantidade de etanol obtido (4ª aula) e da quantidade de $\mathrm{CO}_{2}$ liberado (5⿳a aula) na reação de fermentação, também foram obtidos valores menores de $100 \%$, apesar da determinação de sacarose no mosto ao final da fermentação não indicar mais sua presença. Esses rendimentos de 90,5\% para etanol e $84 \%$ para $\mathrm{CO}_{2}$ podem ser devidos a perdas durante a destilação ou captura do gás, imprecisão em alguma medida, ou ainda ao uso de solução de $\mathrm{HCl}$ não padronizada. Entretanto, através dos dados obtidos, é possível a realização de todos os cálculos estequiométricos envolvidos, o que é suficiente para os objetivos do experimento.

No miniprojeto não são executadas atividades para determinação de constantes fundamentais, o que não permite a classificação como experimento fundamental (F), ${ }^{16}$ sendo que este aspecto é abordado em outras atividades dentro das disciplinas Introdução a Práticas de Laboratório e de Química Geral Experimental, esta última do $2^{\circ}$ semestre, dos cursos de Engenharia Agroindustrial da FURG.

\section{CONCLUSÃO}

A fermentação do caldo de cana se mostrou um tema apropriado para o ensino de Química em disciplinas experimentais iniciais de cursos superiores. É um tema aplicado, de importância para profissionais da área e para a população em geral, o que aumentou o interesse e a motivação dos alunos. A realização das atividades incluídas no miniprojeto permitiu o desenvolvimento de habilidades e conceitos presentes nos componentes curriculares destas disciplinas, podendo o mesmo ser classificado como experimento conceitual (C), metodológico (M) e quantitativo (Q), considerando a classificação proposta por Simoni et al.. ${ }^{16}$

\section{AGRADECIMENTOS}

C. N. Silva, B. T. Santos e T. L. Engelmann agradecem à FURG pelas Bolsas Permanência (04-12/2010) e ao Programa de Educação Tutorial PET 2010/MEC/SESu/SECAD pelas bolsas ao grupo PET/ FURG-SAP-Conexões e Saberes (a partir de 01/2011). 


\section{REFERENCIAS}

1. Crispim, J. E.; Contessi, A. Z.; Vieira, S. A.; Manual da Produção de Aguardente de Qualidade, Livraria e Editora Agropecuária: Guaíba, 2000.

2. Lima, U. A.; Tecnologia das fermentações, Ed. Edgard Blücher: São Paulo, 1975, vol. 1.

3. Soares, R. B.; Dissertação de Mestrado, Universidade Federal Rural do Rio de Janeiro, Brasil, 2010.

4. Brasil, Ministério da Agricultura Pecuária e Abastecimento; Instrução Normativa n. 13 de 29/06/2005, Diário Oficial da União, 30/06/2005, seção 1, p. 3 .

5. http://www.unica.com.br/, acessada em Maio 2012.

6. http://www.biblioteca.sebrae.com.br/bds/BDS.nsf/B142F005A221FDB0 832574DC00457C09/\$File/NT0003905E.pdf, acessada em Maio 2012.

7. http://www.santoantoniodapatrulha.rs.gov.br/prefeitura/, acessada em Maio 2012.
8. Pinheiro, P. C.; Leal, M. C.; Araújo, D. A.; Química Nova na Escola 2003, n. 18, 3

9. Ferreira, E. C.; Montes, R.; Química Nova na Escola 1999, n. 10, 50.

10. Silva, R. O.; Química Nova na Escola 2010, 32, 90.

11. Carriazo, J. G.; Quim. Nova 2011, 34, 1085.

12. Santos, R. S.; Jannuzzi, S. A. V.; Formiga, A. L. B.; Quim. Nova 2010, 33, 1815 .

13. Murtinho, D. M. B.; Serra, M. E. S.; Pineiro, M.; Quim. Nova, 2010, 33, 1805.

14. Simoni, D. A.; Andrade, J. C.; Faigle, J. F. G.; Simoni, J. A.; Quim. Nova 2002, 25, 1034

15. http://www.agricultura.gov.br/portal/page/portal/Internet-MAPA/paginainicial/animal/laboratorios/publicacoes, acessada em Maio 2012.

16. Simoni, D. A.; Andrade, J. C.; Simoni, J. A.; Quim. Nova 2011, 34, 1818. 